九州大学学術情報リポジトリ

Kyushu University Institutional Repository

\title{
Variation in Agronomic Traits of Myanmar' $s$ Major Rice Cultivars in Wet Season and Dry Season
}

FUJII, Tomoyuki

Institute of Tropical Agriculture, Kyushu University

MATSUE, Yuji

Graduate School of Vietnam Academy of Agriculture Science

KUNIHIR0, Yasufumi

Asahikawa, Hokkaido

MYINT, Tin, Tin

Department of Agricultural Research, Yezin, Ministry of Agriculture Livestock and Irrigation 他

https://doi. org/10.5109/2339114

出版情報：九州大学大学院農学研究院紀要. 64 (2)，pp.237-245，2019-09-02. Faculty of Agriculture, Kyushu University

バージョン :

権利関係 : 


\title{
Variation in Agronomic Traits of Myanmar's Major Rice Cultivars in Wet Season and Dry Season
}

\author{
Tomoyuki FUJII ${ }^{1}$, Yuji MATSUE ${ }^{2}$, Yasufumi KUNIHIRO ${ }^{3}$, Tin Tin MYINT ${ }^{4}$, \\ Aye CHIT ${ }^{5}$, Thidar WIN ${ }^{4}$, Htain Lin TUN $^{6}$, Kazuo OGATA ${ }^{1 *}$, Yoshiyuki YAMAGATA ${ }^{7}$, Zaw Moe AUNG ${ }^{4}$, \\ Lu Zaw MYO ${ }^{5}$ and Win Sandar HTAY ${ }^{4}$
}

Institute of Tropical Agriculture, Kyushu University, Fukuoka 819-0395, Japan

(Received May 8, 2019 and accepted May 8, 2019)

\begin{abstract}
In Myanmar, the double cropping area using photoperiod insensitive rice cultivars is gradually expanding with the development of irrigation facilities. However, performance of agronomic traits of these rice cultivars between wet season (WS) and dry season (DS) have not been clarified. The objective of this study is to evaluate variation of heading date, culm length, panicle length, panicle number and paddy yield of rice cultivars in WS and DS, and to identify main components explaining phenotypic variations by genotypes, locations, cropping seasons and year in Myanmar to establish efficient cropping system. We used eight major cultivars (Theedatyin, Manawthukha, Sinthukha, Sinthwelatt, Kyawzeya, Shwewartun, Ayeyarmin and Pawsanyin) and planted in 2014 and 2015 for DS, in 2015 and 2016 for WS. As the results of experiments at three locations; Yezin, Hmawbi and Myaungmya, we found that heading date of all cultivars grown in WS at Yezin and Myaungmya were about 10 to 16 days earlier than those in DS except for Theedatyin, although Yezin is located about $320 \mathrm{~km}$ north of Myaungmya. Further, the difference in heading date between WD and DS was larger in middle matured cultivar group than that of middle/late matured cultivar group at Yezin and Myaungmya. On the other hand, heading dates in WS and DS were almost the same in all cultivars grown at Hmawbi which is located about $100 \mathrm{~km}$ east of Myaungmya. These variations in heading date could be attributed to difference of day and night temperature in WS and DS at each location. Culm length in WS was longer than that of DS in all cultivars at all locations except for 2015 DS at Myaungmya. An air-dry effect is likely to be a cause do this variation. Analysis of variance revealed that phenotypic variance of heading date and culm length was highly associated to genotype, season and location as well as their interactions. Genotypes and interaction of genotypes by season were significant component of phenotypic variance of yield. In analysis of variance separately conducted in WS and DS showed that genotype, location and interaction between genotypes and location were found to be associated to heading date and yield. The results suggest that the cultivar trials at different locations need to be conducted both in WS and DS to improve the efficiency of selection for widely adopted cultivars as well as to make efficient cropping system in Myanmar.
\end{abstract}

Key words: Genotypic variation, $G \times E$ interaction, Monsoon season, Multi-environment trial, Rainfed lowland

\section{INTRODUCTION}

In Myanmar, about $45 \%$ of rice is produced in the southern delta area of Ayeyarwady, Yangon and Bago regions, and about $20 \%$ in the central dry area of Mandalay and Sagain regions where irrigated agriculture

Institute of Tropical Agriculture, Kyushu University, Fukuoka, Japan

Department of Agricultural and Resource Economics, Faculty of Agriculture, Kyushu University, Fukuoka, Japan

Asahikawa, Hokkaido, Japan

${ }^{4}$ Department of Agricultural Research, Yezin, Ministry of Agriculture Livestock and Irrigation, Myanmar

Myanmar Rice Research Centre, Seed Division, Department of Agriculture, Ministry of Agriculture Livestock and Irrigation, Myanmar

${ }^{6}$ Central Research Farm, Department of Agricultural Research, Ministry of Agriculture Livestock and Irrigation, Myanmar

Plant Breeding Laboratory, Faculty of Agriculture, Kyushu University, Fukuoka, Japan

* Corresponding author: Kazuo Ogata, Institute of Tropical Agriculture, Kyushu University, 744, Motooka, Nishi-ku, Fukuoka 819-0395, Japan

E-mail address: kogata@agr.kyushu-u.ac.jp, Tel: +81-92-8024831, Fax: +81-92-802-4833

(事務連絡は092-802-2203も可) has been practiced since the Bagan dynasty (Nemoto, 2014). About $60 \%$ of rice cultivars in Myanmar are referred as High Yielding Variety (HYV) which was extended nationwide through the Whole Township Paddy Production Program (WTPPP) promoted by the government from 1970 s to 1980 s as a national project. The HYV introduction led increase of yield from 1.8 t/ha in 1975 to 3.1 t/ha in 1985 (Khin, 1991). Most of the HYVs are photoperiod insensitive and are grown in both wet season (WS) and dry season (DS). The area of rice production in DS was expanded with an introduction of pump irrigation in the southern delta area. However, rapid increasing of grain yield gradually stagnated and remained at about 3.9 ton /ha in 2015. The reason is conceivable that the cultivars presently grown in each of cropping seasons and location does not fully satisfy the local adaptability of cultivars in addition to less development of irrigation facilities.

It is known that agronomic traits such as heading date, culm length and yield are affected by cropping seasons. There have been several studies on the effect of day length and temperature to these important agronomic traits. Genotypic variation of photoperiod insensitive cultivars for the grain yield in DS is larger than that 
in WS (Sipaseuth et al., 2009). Oka (1954) reported that the growth period of photoperiod insensitive cultivars varies by temperature, however growth period is not extremely shortened at the optimum temperature, unlike the response to the photoperiod of photosensitive cultivars.

Further, the level of performance of agronomic trait is assumed result from genotype $(G)$ of cultivars, environments $(E)$, and interactions between $G$ and $E$ $(G \times E)$. The $G \times E$ interaction is statistically detected when the responses of two genotypes are not consistent to different levels of environment (Allard and Bradshaw, 1964). In rice, the $G \times E$ interaction has been reported in heading date, culm length, grain yield and palatability in different cropping season and location (Oosato et al., 1996; Imabayashi et al., 1997 a, b; Cooper et al., 1999; Sengxua et al., 2017). However, local adaptability of the current major rice cultivars widely grown in Myanmar have not been fully studied by each of crop seasons and locations. To provide the cultivation guideline of cultivars or improve efficiency of the performance test on the recommended cultivars and determine the cropping system, it is essential to evaluate the variations of agronomic traits performances between WS and DS, and it is also useful to examine the $G \times E$ interactions to clarify whether the difference of two or more genotypes under different environments would be consistent or not.

In this study, we evaluated variations of four agronomical traits; heading date, culm length, panicle length, panicle number and paddy yield, using eight major cultivars in Myanmar in WS and DS and dissected phenotypic variances to genotypes and environmental components including interaction by analysis of variance (ANOVA). In the area of double cropping or multi cropping system, heading date is an important trait when selecting the cultivars in consideration of the combination of crops, harvesting time and determine the time of fertilizer application in panicle initiation stage. Culm length is closely related to lodging which effect grain yield and rice quality in rain-fed lowland area. Panicle length and panicle number are directly related to grain yield.

We selected eight major cultivars in Myanmar; Manawthukha (MTK), Sinthukha (STK), Theedatyin (TDY), Sinthwelatt (STL), Kyawzeya (KZY), Shwewartun (SWT), Ayeyarmin (AYM) and Pawsanyin (PSY). Cultivation area of MTK is the largest in Myanmar. Initially, it was popular in irrigated paddy field of central dry zone in 1980s and expanded its acreage in rain-fed low land area of southern delta zone. STK is resistant to Bacterial Leaf Bright (BLB) and crossbred cultivar of MTK and IRBB-21. The Ministry of Agriculture, Livestock and Irrigation (MOALI) is promoting to replace MTK to STK. TDY shows dwarf and early matured phenotypes and is the most popular cultivar in pump irrigated area of southern delta zone in DS. STL is a long grain cultivar and is grown in WS of southern delta zone mainly for exporting to abroad, KZY and SWT are widely grown in northern delta zone. AYM is a long culm rice and is first introduced to Ayeyarwady delta in 1980s then extended to irrigated paddy area of central dry zone such as Sagain region. PSY is characterized by short grain with aroma and is widely grown in Ayeyarwady delta as quality rice and introduced to Shwebo district, Sagain region several years ago. All of them are photoperiod insensitive cultivar except for PSY, which is weak photoperiod sensitive cultivar (Fujii et al., 2017).

\section{MATERIALS AND METHODS}

\section{Plant materials}

Eight major rice cultivars of Myanmar maintained by line cultivation method as breeders' seed in the Department of Agricultural Research (DAR) in Yezin, Nay Pyi Taw, were used in this study (Table 1). The materials were planted in the same methods at three locations as follows. Seeds were treated by fungicide agent Homai WP (Nippon soda Co. Ltd., Japan) and germinated in the seedling bed and transplanted in the paddy fields about 3 weeks after sowing. A plot size was $15.6 \mathrm{~m}^{2}(366 \times 427 \mathrm{~cm})$ and replicated 2 to 3 times in a randomized complete block design. Plating density was $24.5 \times 30.5 \mathrm{~cm}$ and planted single seedling par hill. Sowing and transplanting date are shown in Table 2.

$86.5 \mathrm{~kg} / \mathrm{ha}$ of urea, $98.8 \mathrm{~kg} / \mathrm{ha}$ of triple superphosphate and $24.7 \mathrm{~kg} / \mathrm{ha}$ of potassium chloride were applied as a basal fertilizer. Approximately 15 days before heading, $37.1 \mathrm{~kg} / \mathrm{ha}$ of urea and $24.7 \mathrm{~kg} / \mathrm{ha}$ of potassium chloride were applied as a panicle fertilizer. Nursery and paddy preparation and field management were followed the conventional way of each location. In DS, the eight cultivars were planted in 2014 with 2 replications and in 2015 with 3 replications. In WS, 8 cultivars were planted in 2015 and in 2016 with 3 replications.

\section{Experimental location}

The experiments were conducted at three research farms of MOALI both in WS and DS. These were (1) DAR, Yezin: YZN (N19 82' , E 96 27' ; Meadow alluvial soils), (2) DAR, Myaungmya: MM (16 59', E $94^{\circ} 88^{\prime}$; Gley soils) and (3) Myanmar Rice Research Center at Hmawbi, Department of Agriculture (DOA): HMB (N17 09', E $96^{\circ} 03^{\prime}$; Meadow alluvial soils) (Fig 1).

\section{Trait evaluation}

Heading date is the days from sowing to the date when the panicle is extracted from leaf sheath of 40 50\% hill's main culm in a plot. Panicle length is the average length of the longest culm of the each 20 hills in a plot. Panicle number is the average number of effective tiller of the each 20 hills in a plot. For paddy yield data 30 hills showing moderate growth in a plot were harvested and dried in paddy up to $13-15 \%$ of moisture contents in grains. After winnowing and controlling the moisture content to $14 \%$, the yield were weighted.

\section{Statistical analysis}

The data of the eight cultivars grown under various environmental conditions (cropping season, location and year) were analyzed by type II analysis of variance 
Table 1. Outline of the cultivars

\begin{tabular}{|c|c|c|c|c|c|c|}
\hline \multirow{2}{*}{$\begin{array}{l}\text { Earliness in wet } \\
\quad \text { season }^{1)}\end{array}$} & \multirow{2}{*}{ Cultivar $^{2)}$} & \multirow{2}{*}{ Culm length } & \multirow{2}{*}{ Genealogy } & \multirow{2}{*}{ Origin $^{3)}$} & \multicolumn{2}{|c|}{ Sowing area $(\%)^{4)}$} \\
\hline & & & & & WS & DS \\
\hline Early & Theedatyin (TDY) & Short & IR $13240-108-2-2-3$ & Philippines & 2.7 & 45.1 \\
\hline Middle & Manawthukha (MTK) & Short & Mashuri-M & Malaysia & 18.1 & 9.5 \\
\hline Middle & Sinthukha (STK) & Short & Mashuri-M/IR BB-21 & DAR & 8.9 & 6.6 \\
\hline Middle & Sinthwelatt (STL) & Medium & IR 53936-60-3-2-3-1 & Philippines & 4.1 & 0.4 \\
\hline Middle/Late & Kyawzeya (KZY) & Medium & X70-18-32 (IR5/Aungzeya) & DAR & 3.0 & - \\
\hline Middle/Late & Shwewartun (SWT) & Long & IR-5 $\gamma$-lay mutant & DAR & 4.7 & - \\
\hline Middle/Late & Ayeyarmin (AYM) & Long & Machando & Malaysia & 5.3 & - \\
\hline Middle/Late & Pawsanyin (PSY) & Long & Pawsan group & Local var. & 8.5 & - \\
\hline
\end{tabular}

${ }^{1)}$ Early, middle and middle/Late indicate earliness less than 125 days, from 126 to 135 days and from 135 to 150 days, respectively.

${ }^{2)}$ Cultivars abbreviations are written in parenthesis.

${ }^{3)}$ DAR represents Department of Agricultural Research.

${ }^{4)}$ WS and DS represent wet and dry seasons, respectively.

Table 2. Sowing and transplanting date of three locations from dry season in 2014 to wet season in 2016

\begin{tabular}{|c|c|c|c|c|c|}
\hline \multirow{2}{*}{ Year } & \multirow{2}{*}{ Season } & \multirow{2}{*}{ Treatment } & \multicolumn{3}{|c|}{ Location } \\
\hline & & & Yezin & Hmawbi & Myaungmya \\
\hline \multirow[t]{2}{*}{2014} & Dry & Sowing & 12.16.2014 & 12.16.2014 & 12.22 .2014 \\
\hline & & Transplanting & 01.08 .2015 & 01.09.2015 & 01.13 .2015 \\
\hline \multirow[t]{2}{*}{2015} & Wet & Sowing & 07.07 .2015 & 07.07 .2015 & 07.04 .2015 \\
\hline & & Transplanting & 07.29 .2015 & 07.30 .2015 & 07.24 .2015 \\
\hline \multirow[t]{2}{*}{2015} & Dry & Sowing & 12.18 .2015 & 12.17 .2015 & 12.18 .2015 \\
\hline & & Transplanting & 01.15 .2016 & 01.12 .2016 & 01.15 .2016 \\
\hline \multirow[t]{2}{*}{2016} & Wet & Sowing & 06.28 .2016 & 06.24 .2016 & 06.25 .2016 \\
\hline & & Transplanting & 07.20 .2016 & 07.15 .2016 & 07.16 .2016 \\
\hline
\end{tabular}
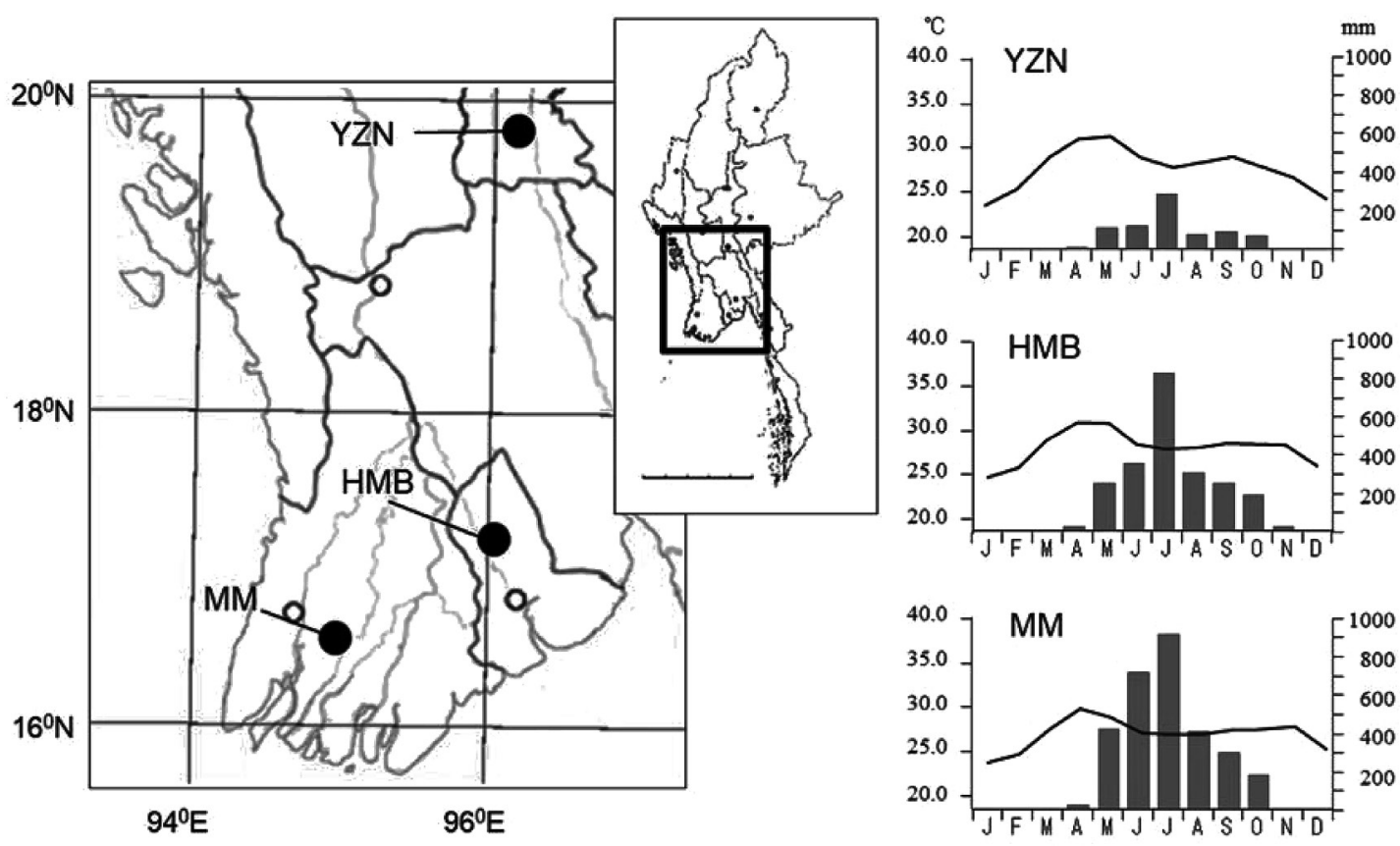

Fig. 1. Study sites and the climate. YZN, HMB and MM represent Yezin, Hmawbi and Myaungmya, respectively. The data is cited from Department of Metrology and Hydrology, Ministry of Transport in 2015. 
(ANOVA) using linear model and package 'car' in $\mathrm{R}$ (https://www.r-project.org/). The $G \times E$ interaction in heading date, culm length, panicle length, panicle number and paddy yield were analyzed by two-way analysis of variance with replication to determine the level of significance and percentage of contribution of each component to the total variation.

\section{RESULTS}

\section{Phenotypic differences by genotypes, crop seasons and locations}

To clarify phenotypic variations of TDY, MTK, STK, STL, KZY, SWT, AYM, and PSY under the different environmental conditions defined by cropping seasons, locations and years, we planted these eight cultivars at three locations in DS of 2014 and 2015 and in WS of 2015 and 2016, and evaluated heading date, culm length, panicle length, panicle number and paddy yield (Tables 1 and 2, Fig. 1).

Heading date of all cultivars in WS was significantly earlier than that of DS at YZN. The middle/late cultivars, KZY, SWT, AYM and PSY showed 12.8 days (ranging from 10.8 to 15 days) of early heading in WS as compared with ones in DS (Table 3). The middle cultivars, MTK, STK and STL, exhibited approximately $22-23$ days of early heading in WS as compared with ones in DS, (Table 3 and Fig. 2A). Similarly to YZN, the same tendency was observed in MM except for TDY. TDY showed significantly earlier heading in WS than DS, but in YZN heading date were not significantly different between DS and WS conditions in MM. (Table 3 and Fig. 2B). In contrast with YZN and MM, significant difference in heading date between DS and WS at HMB was not found except for MTK, STL and SWT. The differences of heading date between DS and WS were included within 6 days for all cultivars (Table 3 and Fig. 2C).

Culm length in WS was significantly longer than that of DS in all cultivars at three locations except for AYM, MTK and STK at MM (Table 3 and Fig. 2D-F), suggesting that culm length in WS showed longer than that of DS at all location. The elongation of culm length in WS than that in DS is apparent in cultivars showing longer culm length. The medium or medium/long culm cultivars such as STL, KZY, SWT, AYM and PSY showed $22.4 \mathrm{~cm}$ of longer culm length in WS as compared with DS on average. Whereas, culm length of short culm cultivars such as TDY, MTK and STK in WS were only $10.8 \mathrm{~cm}$ shorter in DS on average although culm length at three locations was not much different for all cultivars both in DS and WS.

For panicle length in WS, TDY at three locations and KZY at HMB were significantly longer than those of DS respectively. And the variation of panicle length in WS and DS at three locations was not much different for all cultivars except for MM in WS (Table 3 and Fig. 2G-I).

From Table 3 and Fig. 2J-L, panicle number of all cultivars at YZN did not show significant difference between WS and DS whereas panicle number of MTK, STL, KZY and SWT in WS at MM were smaller than that of DS and STK, SWT and PSY in WS at HMB were larger than those of DS.

Regarding the yield, AYM in WS at YZN was higher than that of DS significantly whereas yields of AYM was higher in DS than in WS at HMB. MTK in WS at YZN showed significantly lower yield than that of DS whereas MTK exhibited higher yields in WS than in DS at HMB. The yield of SWT in WS at YZN and HMB was significantly higher than that of DS (Table 3). The yields of short culm cultivars TDY, MTK and STK in DS were higher than those in WS at YZN and MM, whereas the yields of these cultivars at HMB were higher in WS than those in DS (Fig. 2M-O). In DS, the short culm cultivars tended to show superior yield than the middle/long culm cultivars at YZN and MM while vice versa at HMB. In 2015 DS, short culm cultivars TDY, MTK and STK showed the highest yield at YZN and the lowest at HMB. In 2016 WS, the yield of all cultivars at HMB and MM showed similar trend, while at YZN, the yields of middle/ long culm cultivars STL, KZY, SWT and AYM were the highest among three locations.

\section{$G \times E$ interaction using ANOV}

Phenotypic differences were observed by genotype $(G)$, cropping seasons $(S)$ and locations $(L)$, suggesting that the observed phenotypic variance $(P)$ were possible to be divided by main effect of $G$ and environmental components of $S$ and $L$ and their interactions. This implied that optimization of cultivars selections by cropping seasons and locations is indicated by consideration of varietal characteristics based on ANOVA. Assuming that phenotypic values of heading date, culm length, panicle length, panicle number and yield denoted as $P$ were explained by main effects of $G, L$ and $S$ including interaction between $G$ and $L(G \times L)$ and between $G$ and $S(G \times S)$. Therefore, we assumed that phenotypic variance components could be dissected by ANOVA using the linear model equation $P \sim G+L+S+G \times L+G \times S$ (Table 4). This model represented the best fit among the other reduced model according to akaike information criteria (data not shown). Table 4 shows that main effects of $G, L$ and $S$ as well as $G \times S$ and $G \times L$ interactions were highly associated to heading date and panicle length. Culm length was significantly explained by $G, L$ and $\mathrm{S}$ as well as $G \times S$. For panicle number, significant variations for $G, L$ and $G \times S$ were found. For yield, significant effect of $G$ and $G \times S$ interaction were detected. Since $G \times S$ interaction highly associated in all agronomic traits, ANOVA were conducted separately into WS and DS including fixed effect by year $(Y)$ for two years' replication using model equation, $P \sim G+L+Y+G \times L$ (Table 5). Genotypes were main effect in all agronomic traits in WS and DS. For heading date, variations of $L$ as well as $G \times L$ interaction were highly significant both in WS and DS whereas $Y$ was not significantly affected in both cropping seasons. For culm length, significant variation for $L$ and $G \times L$ were detected in WS, while in DS, variations of $L$ and $Y$ were highly significant, but $G \times L$ interaction was not significantly affected in DS. For Panicle length, variation of $Y$ was significant in WS and DS whereas effect of 
Table 3. $t$-test for tesintg differences in heading time, culm length, panicle length, panicle number and yield of eight cultivars between wet and dry season at three locations

\begin{tabular}{|c|c|c|c|c|c|c|c|c|c|}
\hline \multirow[b]{3}{*}{ Phenotype $^{3)}$} & \multirow[b]{3}{*}{ Cultivars $^{4)}$} & \multicolumn{8}{|c|}{ Phenotypic value ${ }^{1,2)}$} \\
\hline & & \multicolumn{2}{|r|}{ Yezin } & \multicolumn{3}{|c|}{ Myaungmya } & \multicolumn{3}{|c|}{ Hmawbi } \\
\hline & & DS & WS & DS & WS & & DS & WS & \\
\hline \multirow{8}{*}{$\mathrm{HD}$} & TDY & 94.4 & $83.0 * * * 2)$ & 81.2 & 82.0 & & 87.4 & 89.2 & \\
\hline & MTK & 115.8 & $94.3 * * *$ & 108.2 & 93.3 & $* * *$ & 105.8 & 100.0 & $* * *$ \\
\hline & STK & 116.6 & $95.0 * * *$ & 110.2 & 94.7 & $* * *$ & 106.2 & 103.7 & \\
\hline & STL & 116.6 & $93.8 * * *$ & 109.8 & 94.7 & $* * *$ & 104.2 & 101.2 & $*$ \\
\hline & $\mathrm{KZY}$ & 119.6 & $105.5 * * *$ & 116.8 & 108.5 & $* * *$ & 113.0 & 111.5 & \\
\hline & SWT & 123 & $112.2 * *$ & 119.0 & 112.3 & $* * *$ & 114.8 & 120.3 & $* *$ \\
\hline & AYM & 127.2 & $112.2 * * *$ & 121.2 & 113.8 & $* * *$ & 119.2 & 118.5 & \\
\hline & PSY & 118.6 & $107.5 * * *$ & 125.0 & 114.8 & $* * *$ & 115.4 & 118.5 & \\
\hline \multirow{8}{*}{ CL } & TDY & 56.9 & $74.4 * * *$ & 60.3 & 71.4 & $* *$ & 57.0 & 70.2 & $* *$ \\
\hline & MTK & 72.1 & $88.8 * *$ & 79.0 & 82.3 & & 75.6 & 88.1 & $* * *$ \\
\hline & STK & 79.8 & $92.4 * *$ & 83.8 & 84.7 & & 80.3 & 92.6 & $* * *$ \\
\hline & STL & 82.3 & 108.6 **** & 92.2 & 108.2 & $* * *$ & 89.7 & 112.2 & $* * *$ \\
\hline & $\mathrm{KZY}$ & 82.9 & $108.3 * * *$ & 94.7 & 109.4 & $*$ & 86.4 & 114.7 & $* * *$ \\
\hline & SWT & 95.5 & $117.3 * * *$ & 100.8 & 113.6 & $*$ & 95.0 & 123.8 & $* * *$ \\
\hline & AYM & 110.1 & $135.2 * * *$ & 118.2 & 137.2 & & 120.8 & 145.3 & $*$ \\
\hline & PSY & 89.2 & $116.6 * * *$ & 94.3 & 124.2 & $* * *$ & 95.1 & 126.4 & $* * *$ \\
\hline \multirow{8}{*}{ PL } & TDY & 23.5 & $26.0 *$ & 23.3 & 25.2 & $* *$ & 22.2 & 27.0 & $* * *$ \\
\hline & MTK & 22.7 & $24.8 *$ & 23.1 & 25.1 & & 22.9 & 24.5 & \\
\hline & STK & 24.3 & 25.4 & 26.2 & 28.5 & & 24.6 & 25.0 & \\
\hline & STL & 31.0 & 31.5 & 28.7 & 29.2 & & 31.1 & 31.2 & \\
\hline & $\mathrm{KZY}$ & 27.9 & 28.4 & 28.4 & 29.0 & & 28.0 & 30.9 & $* * *$ \\
\hline & SWT & 29.3 & 29.4 & 30.3 & 31.2 & & 28.6 & 29.2 & \\
\hline & AYM & 28.4 & 26.8 & 26.5 & 23.9 & $*$ & 25.9 & 26.9 & $*$ \\
\hline & PSY & 26.7 & 26.3 & 26.8 & 29.0 & & 27.7 & 28.0 & \\
\hline \multirow{8}{*}{ PN } & TDY & 11.9 & 15.2 & 14.5 & 13.8 & & 15.0 & 18.5 & \\
\hline & MTK & 16.8 & 16.2 & 17.2 & 15.1 & * & 19.4 & 19.4 & \\
\hline & STK & 14.9 & 16.9 & 15.2 & 14.4 & & 17.1 & 19.8 & $*$ \\
\hline & STL & 13.4 & 13.7 & 14.3 & 12.2 & * & 14.5 & 14.4 & \\
\hline & $\mathrm{KZY}$ & 13.6 & 13.3 & 14.6 & 11.8 & * & 12.9 & 14.3 & \\
\hline & SWT & 14.5 & 13.1 & 14.8 & 11.9 & * & 13.3 & 14.7 & $*$ \\
\hline & AYM & 15.8 & 17.1 & 15.1 & 15.9 & & 18.2 & 17.6 & \\
\hline & PSY & 12.0 & 13.8 & 13.6 & 12.9 & & 13.4 & 16.6 & $* *$ \\
\hline \multirow{8}{*}{ YD } & TDY & 2004.0 & 1460.8 & 2303.3 & 1484.3 & & 1617.6 & 1807.1 & $* *$ \\
\hline & MTK & 2043.5 & $1719.3 * *$ & 2326.4 & 1771.6 & & 1576.6 & 1981.5 & $* *$ \\
\hline & STK & 2369.1 & $1901.6 *$ & 2531.1 & 1969.1 & & 1698.2 & 2014.6 & \\
\hline & STL & 2081.9 & 2230.7 & 2169.1 & 1759.1 & & 2059.8 & 1807.4 & \\
\hline & $\mathrm{KZY}$ & 1845.7 & 2200.3 & 2012.5 & 1943.1 & & 1600.2 & 1772.5 & \\
\hline & SWT & 1031.1 & $2298.4 * * *$ & 1761.9 & 2017.9 & & 1403.0 & 1982.1 & $* *$ \\
\hline & AYM & 1316.2 & $2186.6 * *$ & 938.5 & 1638.9 & & 2125.8 & 1484.3 & $* *$ \\
\hline & PSY & 1825.7 & 1516.2 & 1229.6 & 1560.3 & & 1616.8 & 1375.5 & \\
\hline
\end{tabular}

1) WS and DS represent wet and dry seasons, respectively.

2) $*$, **, and $* * *$ represent significance at $5 \%, 1 \%$, and $0.1 \%$ level, respectively.

${ }^{3)} \mathrm{HD}, \mathrm{CL}, \mathrm{PL}, \mathrm{PN}$ and YD represent heading date, culm length, panicle length, panicle number and yield respectively.

4) TDY, MTK, STK, STL, KZY, SWT, AYM and PSY indicates cultivar names of Theedatyin, Manauthukha, Sinthukha, Sinthwelatt, Kyawzeya,

Shwewartun, Ayeyarmin and Pawsanyin, respectively. 
YZN

A

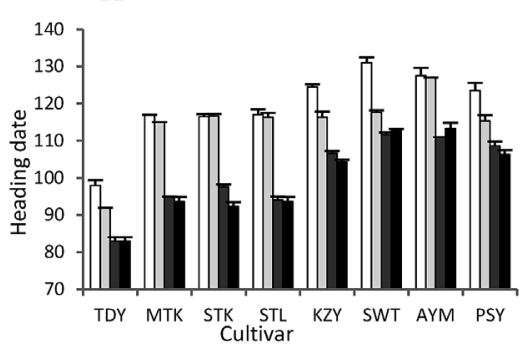

D

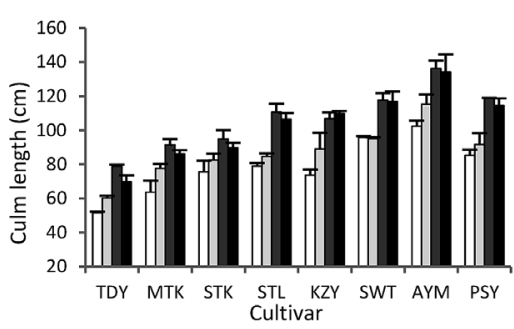

G

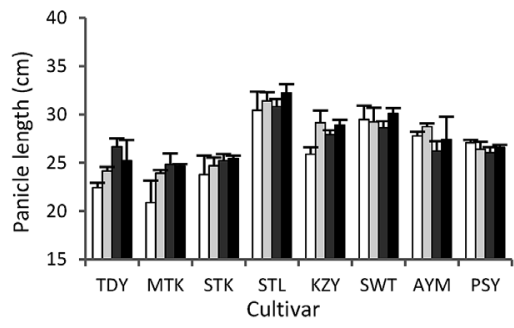

J

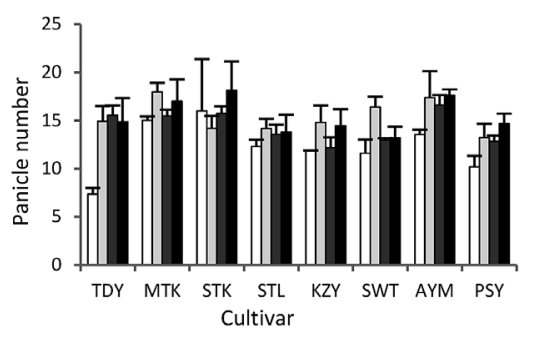

M

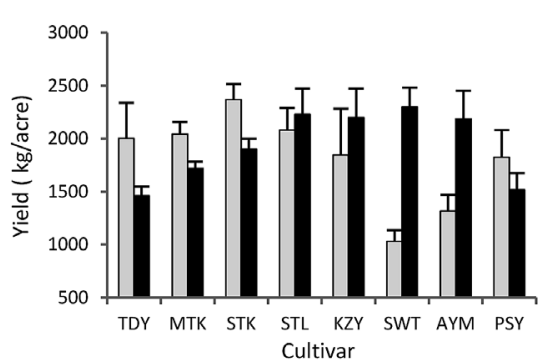

MM

B

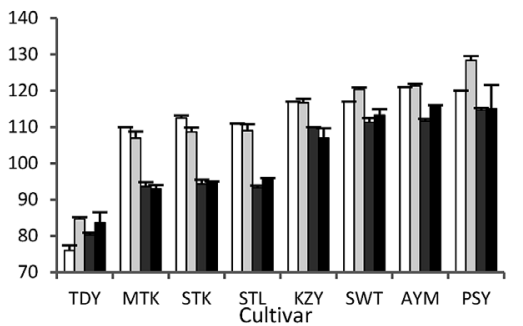

E

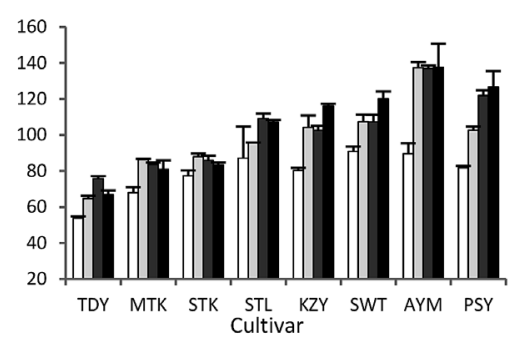

$\mathrm{H}$

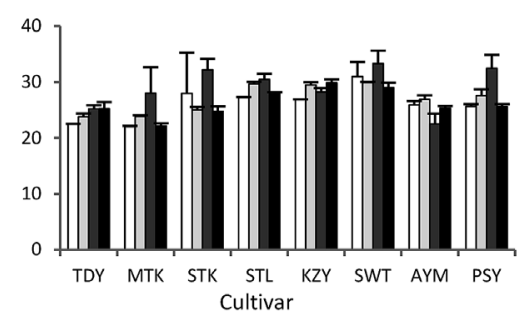

K

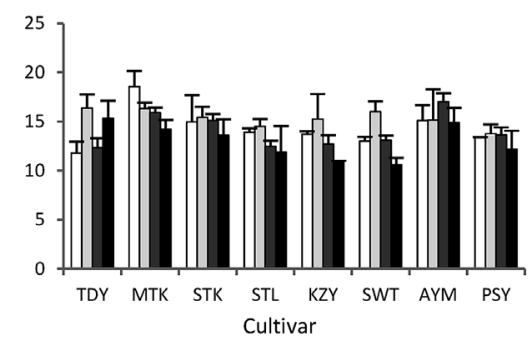

$\mathrm{N}$

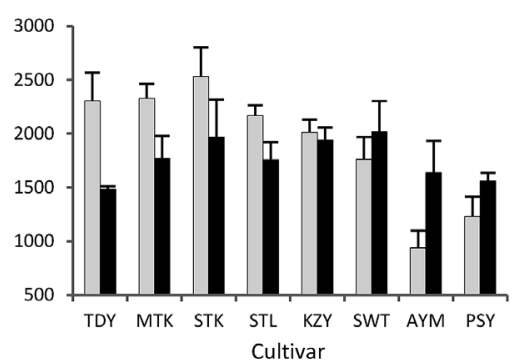

HMB

C

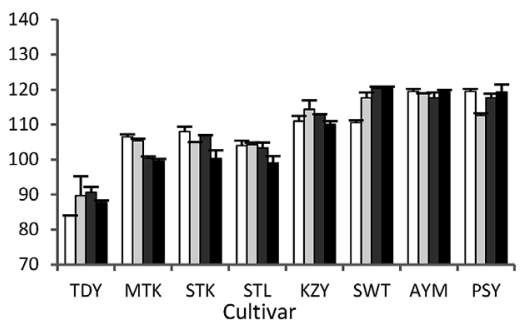

F

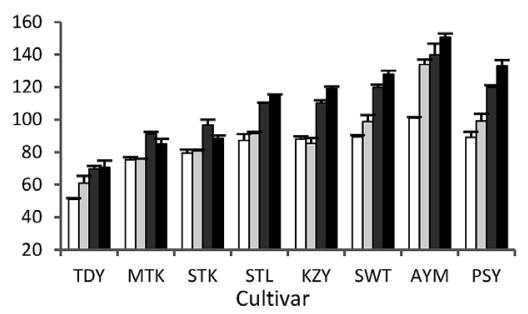

I

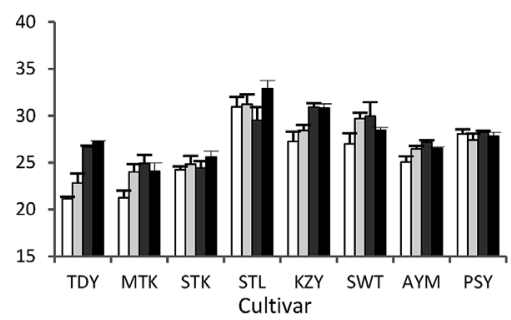

L

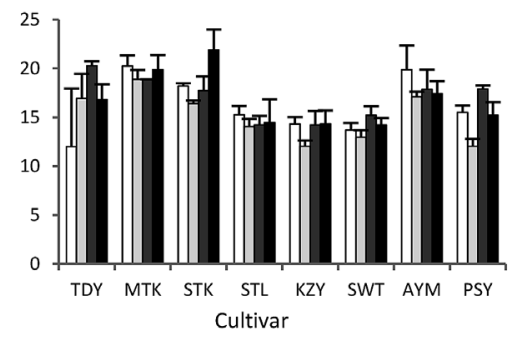

O

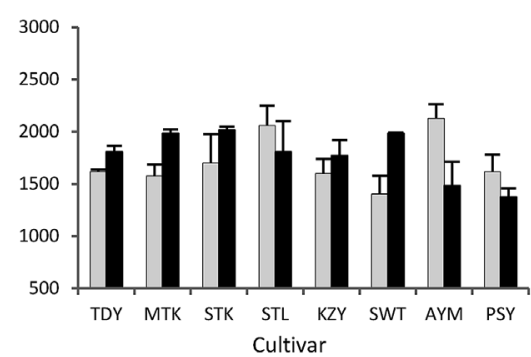

Fig. 2. Phenotypic values obtained in wet and dry seasons from 2014 to 2016 by locations.

A-C: Heading date. D-F: Culm length. G-I: Panicle length. J-L: Panicle number. M-O: Yield. A, D, G, J, M: Yezin. B, E, H, K, N: Myaungmya. C, F, I, L, O: Hmawbi. Values in 2014 in dry season, in 2015 in wet season, in 2015 in dry season and in 2016 in wet season were represented with round white $(\square)$, light gray color $(\square)$, dark gray color $(\square)$ and black ( $\square$ ), respectively. Error bars indicate standard error of mean. 
Table 4. Analysis of variance of the four agronomic traits by genotype, location and cropping season

\begin{tabular}{|c|c|c|c|c|}
\hline Trait & Component ${ }^{1)}$ & $d f$ & $M S$ & \\
\hline \multirow[t]{6}{*}{ Heading date } & $G$ & 7 & 3893.7 & $* * * 2)$ \\
\hline & $L$ & 2 & 89.0 & $* *$ \\
\hline & $S$ & 1 & 4949.5 & $* * *$ \\
\hline & $G \times S$ & 7 & 160.5 & $* * *$ \\
\hline & $G \times L$ & 14 & 48.1 & $* *$ \\
\hline & Residuals & 232 & 18.9 & \\
\hline \multirow[t]{6}{*}{ Culm length } & $G$ & 7 & 12519.4 & $* * *$ \\
\hline & $L$ & 2 & 346.0 & $* *$ \\
\hline & $S$ & 1 & 23405.4 & $* * *$ \\
\hline & $G \times S$ & 7 & 41.6 & $* * *$ \\
\hline & $G \times L$ & 14 & 62.3 & \\
\hline & Residuals & 232 & 59.3 & \\
\hline \multirow[t]{6}{*}{ Panicle length } & $G$ & 7 & 186.9 & $* * *$ \\
\hline & $L$ & 2 & 0.5 & \\
\hline & $S$ & 1 & 66.5 & $* * *$ \\
\hline & $G \times S$ & 7 & 12.0 & $* * *$ \\
\hline & $G \times L$ & 14 & 12.0 & $* * *$ \\
\hline & Residuals & 232 & 3.0 & \\
\hline \multirow[t]{6}{*}{ Panicle number } & $G$ & 7 & 83.6 & $* * *$ \\
\hline & $L$ & 2 & 110.6 & $* * *$ \\
\hline & $S$ & 1 & 4.4 & \\
\hline & $G \times S$ & 7 & 11.8 & $* *$ \\
\hline & $G \times L$ & 14 & 5.6 & \\
\hline & Residuals & 232 & 4.0 & \\
\hline \multirow[t]{6}{*}{ Yield } & $G$ & 7 & 575714.9 & $* * *$ \\
\hline & $L$ & 2 & 220011.0 & . \\
\hline & $S$ & 1 & 494.0. & \\
\hline & $G \times S$ & 7 & 53964.6 & $* * *$ \\
\hline & $G \times L$ & 14 & 167357.7 & $*$ \\
\hline & Residuals & 106 & 82308.5 & \\
\hline
\end{tabular}

1) $G, L$ and $S$ represent variance components of genotype, location and cropping season, respectively. Interactions between $G$ and $S$, and $G$ and $L$ are shown by $G \times S$ and $G \times S$, respectively.

2) *, **, and *** represent significance at $5 \%, 1 \%$, and $0.1 \%$ level, respectively.

$L$ was not found in both cropping season. $G \times L$ interaction was highly significant in WS and DS. For panicle number, variation of $L$ was significant in WS and DS. $G \times L$ interaction was not affected in WS and DS. For yield, significant variations were found for $L$ and $G \times L$ interaction both in WS and DS. Effect of $Y$ for culm length, panicle length and panicle number in DS was larger than those in WS.

\section{DISCUSSION}

In this study, we investigated the variations in agronomic traits of Myanmar's eight major rice cultivars in WS and DS. The experiments were held two consecu- tive years from 2014 DS to 2016 WS at three locations.

As the result of series of experiments, we found that effect of $S$ as well as $G \times S$ for heading date were highly significant. Further, both in WS and DS, variations of $G$ and $L$, as well as $G \times L$ interaction were highly significant for heading date and all cultivars varied greatly at every location.

Heading date in WS at YZN and MM were about 10-16 days earlier than those in DS, and these two locations showed similar tendency in heading date although YZN and MM are $320 \mathrm{~km}$ away in the north and south. Conversely at HMB, the difference of heading date between WS and DS was only 0.4 days although HMB is located at almost the same longitude and altitude as MM. This tendency was remarkable in Manawthukha (MTK), Sinthukha (STK) and Sinthwelatt (STL) of middle matured cultivar group. Since all the cultivars used in this study were photoperiod insensitive and weak sensitive cultivars, the differences of heading date is probably due to not day length but maximum (max.) and minimum (min.) temperature (temp.) in WS and DS at each location rather than day length. In WS, the min. temp. (night temp.) of HMB from June to September was approx. $2.0^{\circ} \mathrm{C}$ higher than that of MM (Fig.2). Therefore, it is likely that the high night temp. at HMB delayed heading date. According to previous studies, heading date delay under the high night temp. (Nakayama and Kiyosawa, 1955). On the otherhand in DS, the heading date at HMB was earlyer than that of MM. The max. temp. (day temp.) of HMB from December to March was approx. $1.7^{\circ} \mathrm{C}$ higher than that of MM (Fig.2). It is likely that the high day temp. at HMB promoted heading date (Nakayama and Kiyosawa, 1954). At YZN, it is likely that heading date was promoted by the high day temp. in WS and delayed by the low night temp. in DS among three locations.

Culm length of all cultivars was also greatly affected by the cropping season. We found that effect of $S$ as well as $G \times S$ interaction for culm length was highly significant. Further, both in WS and DS, variations of $G$ and $L$ were highly significant for culm length, however $G \times L$ interaction was detected only in WS. The culm length in WS was on average of $20.3 \mathrm{~cm}$ longer than that in DS at every location. Particularly, this tendency was remarkable in middle/long culm cultivars compared to short culm cultivars. These results contrast with the previous study that the culm length becomes longer as the number of days to flowering increase (Sato, 1987). However, that study was conducted under short day condition using photoperiodic sensitive cultivars, hence this contradiction could be attributed to the difference of vegetative and reproductive growth period between photoperiodic sensitive and insensitive cultivars. Other studies have shown that culm lengh elongate by increasing nitrogen uptake caused by the air-drying effect of soil. In double cropping area, culm length and panicle number increase in WS because of the effect of pre-planting soil-drying in DS (Nozaki, 1983; Sasaki, et al., 2001; Ventura and Watanabe 1978). Accordingly, even in this experiment, it is possible that the culm length in WS became longer 
Table 5. Analysis of variance of interaction between genotype and location by cropping seasons

\begin{tabular}{|c|c|c|c|c|c|c|c|}
\hline \multirow{2}{*}{ Trait } & \multirow{2}{*}{ Component } & \multicolumn{3}{|c|}{$\mathrm{WS}^{1)}$} & \multicolumn{3}{|c|}{$\mathrm{DS}^{1)}$} \\
\hline & & $d f$ & $M S$ & & $d f$ & $M S$ & \\
\hline \multirow[t]{5}{*}{ Heading date } & $G$ & 7 & 2257.7 & $* * *$ & 7 & 1796.5 & $* * *$ \\
\hline & $L$ & 2 & 750.4 & $* * *$ & 2 & 688.3 & $* * *$ \\
\hline & $Y$ & 1 & 10.6 & & 1 & 24.6 & \\
\hline & $G \times L$ & 14 & 15.5 & $* * *$ & 14 & 48.8 & $* * *$ \\
\hline & Residuals & 119 & 4.0 & & 95 & 9.9 & \\
\hline \multirow[t]{5}{*}{ Culm length } & $G$ & 7 & 8643.3 & $* * *$ & 7 & 4262.5 & $* * *$ \\
\hline & $L$ & 2 & 368.5 & $* * *$ & 2 & 467.9 & $* * *$ \\
\hline & $Y$ & 1 & 25.0 & & 1 & 4257.4 & $* * *$ \\
\hline & $G \times L$ & 14 & 64.4 & $* *$ & 14 & 28.2 & \\
\hline & Residuals & 119 & 28.5 & & 95 & 51.1 & \\
\hline \multirow[t]{5}{*}{ Panicle length } & $G$ & 7 & 84.9 & $* * *$ & 7 & 113.9 & $* * *$ \\
\hline & $L$ & 2 & 3.2 & & 2 & 1.5 & \\
\hline & $Y$ & 1 & 17.4 & $*$ & 1 & 36.1 & $* * *$ \\
\hline & $G \times L$ & 14 & 11.3 & $* * *$ & 14 & 4.2 & $* *$ \\
\hline & Residuals & 119 & 3.5 & & 95 & 1.8 & \\
\hline \multirow[t]{5}{*}{ Panicle number } & $G$ & 7 & 55.4 & $* * *$ & 7 & 40.1 & $* * *$ \\
\hline & $L$ & 2 & 141.2 & $* * *$ & 2 & 18.7 & * \\
\hline & $Y$ & 1 & 0.2 & & 1 & 31.0 & $*$ \\
\hline & $G \times L$ & 14 & 3.4 & & 14 & 5.4 & \\
\hline & Residuals & 119 & 2.6 & & 95 & 4.6 & \\
\hline \multirow[t]{5}{*}{ Yield } & $G$ & 7 & 384584.3 & $* * *$ & 7 & 730635.7 & $* * *$ \\
\hline & $L$ & 2 & 215916.5 & $* *$ & 2 & 215917.0 & $* *$ \\
\hline & $Y$ & - & - & & - & - & \\
\hline & $G \times L$ & 14 & 111758.7 & $* * *$ & 14 & 400162.7 & $* *$ \\
\hline & Residuals & 44 & 35038.9 & & 46 & 39199.9 & \\
\hline
\end{tabular}

1) $*, * *$, and $* * *$ represent significance at $5 \%, 1 \%$, and $0.1 \%$ level, respectively.

than that in DS because there was the soil air-drying effect in DS at every location.

As regard to the yield, since $G \times S$ interaction was highly significant. The yields of short culm cultivars groups in DS tended to be higher than those in WS at YZN and MM, in contrast the yields of these cultivars at HMB were lower in DS. The results indicated that there was a tendency for the yields of short culm cultivars and middle/long culm cultivars to be reversed between WS and DS at three locations. The effect of soil air-drying was not found in the yield in this study. We also found that the yield was varied depend on cropping season and location as well as the culm length type or earliness of the cultivar. These results are different from the previous study that genotype variation for yield is significant in DS, while genotype variation is small and often not significant in WS (Sipaseuth, et al., 2009). The reason could be attributed to the use of different genotype and different environment condition for each experiment. Since the data collected for the evaluation of the yield in this study was only single year both in WS and DS, therefore, further studies to analyze the variations of the yield and its components as well as their $G \times E$ interaction in the yield are required for more than 2 years.

The results of this study demonstrated that heading date, culm length and paddy yield varies largely depending upon cropping season and location. It also indicates that the varietal. differences by cropping season and location vary depending upon earliness or the type of culm length. In addition, this study suggests that the day and night temperatures in WS and DS dominate the heading date of photoperiod insensitive cultivars.

In conclusion, we propose that the variations of agronomic traits such as heading date, culm length and paddy yield between WS and DS must be studied for the selection of cultivars in double cropping and multiple cropping regions.

\section{ACKNOWLEDGEMENTS}

We thank the Department of Agricultural research and Department of Agriculture, Ministry of Agriculture Livestock and Irrigation for providing support for conducting this experiment. Valuable suggestions by Dr. Y. 
Yamamoto, JICA expert of Yezin Agricultural University for the preparation of this manuscript is also acknowledged. This work was partly supported by Japan Science and Technology Agency (JST) /Japan International Cooperation Agency (JICA), Science and Technology Research Partnership for Sustainable Development (SATREPS).

\section{REFERENCES}

Allard, R.W. and A.D.Bradshaw 1964. Implecation of genotypeenvironment interaction in applied plant breeding. Crop Sci. 4: $503-508$

Cooper, M., S. Rajatasereekul, S. Immark, S. Fukai and J. Basnayake 1999. Rainfed lowland rice breeding strategies for Northeast Thailand.: 1. Genotypic variation and genotype $\times$ environment interactions for grain yield. Filed Crops Res. 64: $131-151$

Fujii T., Y. Yamamoto, K. Ogata and A. Yoshimura, 2018. Rice varieties in Myanmar: Current situation of breeding and distribution. Jpn. Res. Trop. Agr. 11(2): 60-72

Imahayashi, S., Y. Matsue, Y. Hamachi and T. Yoshida 1997a. Genotype $\times$ environment interaction by for early-maturing rice cultivar with high palatability in northern Kyushu. I. Yeild. Jpn. J. Crop Sci. 66: $538-544$

Imahayashi, S., Y. Matsue, Y. Hamachi and T. Yoshida 1997b. Genotype $\times$ environment interaction by for early-maturing rice cultivar with high palatability in northern Kyushu. II. Heading date and culm length. Jpn. J. Crop Sci. 66: 545-550

Khin Win, 1991. A century of rice improvement in Burma. IRRI, Manila. pp.162

Nakayama, H. and S. Kiyosawa, 1955. Effect of high night temperature upon the growth and heading of rice plants. Jpn. J. Crop Sci. 23(3): 198-199

Nemoto, K. 2014. The story: History of Burma - from the dynasty to the present, Chuokoron-sha. pp.472

Nozaki, M. 1983. Studies on Technology of cultural practices for rice double cropping in Malaysia, VII. Effect of Pre-planting Soil drying on Growth and Yield of Rice in the Muda Irrigation Area. J pn. J. Trop. Agr. 27(1): 8-13

Oka, H. 1954. Variet al. variation of the responses to day-length and temperature and the number of days of growth period. (Phylogenic differentiation of the cultivated rice plant. III). Jpn. J. Breed. 4: 92-100

Oosato, K.F., Y. Hamachi, Y. Matsue and T. Yoshida, 1996. Genotype $\times$ environment interaction of palatability in rice. Jpn. J. Crop Sci. 65(4): 585-589

Sasaki, R., T. Horie, K. Toriyama and Y. Shibata 2001. Factors affection the yearly fluctuation in the culm length of rice. Jpn. J. Crop Sci. 70(4): 489-498

Sato, Y. 1987. Effect of days to heading on culm length of rice plants, Jpn. J. Breed. 37: 88-97

Sengxua, P., B.K. Samson, C. Bounphanousay, S. Xayavong, K. Douangboupha, D. Harnpichitvitaya, T.M. Jackson and L.J. Wada, 2017. Adaptation of rice (Oryza sativa L.) genotypes in the rainfed lowland of Lao PDR. Plant Prod. Sci. 20(4): $477-484$

Sipaseuth, J. Basnayake, S. Fukai, P. Inthapanya and M. Changphengxay 2009. Consistency of genotypic performance of lowland rice in wet and dry season in Lao PDR. Field Crops Res. 111: 47-54

Ventura, W., I. Watanabe 1978. Dry season soil condition and soil nitrogen availability to wet season wetland rice. Soil Sci. Plant Nutr. 24(4): 535-545

\section{AUTHOR CONTRIBUTION}

T. Fujii designed the study, carried out the experiments, collected data, analyzed data and wrote the first draft. Y. Matsue, Y. Kunihiro, K. Ogata and Y. Yamagata analyzed the data, wrote and revised manuscript. Tin Tin Myint, Aye Chit, Thidar Win and Htain Lin Tun collected and analyzed the data. Zaw Moe Aung, Lu Zaw Myo and Win Sandar Htay carried out the experiments, collect and analyzed the data. 
